\title{
Study on Three-dimensional Geological Modeling in Xingshugang Oil Field
}

\author{
Tingting $\mathrm{He}^{1, \text { a }}$, Xin Tan ${ }^{1,2, \mathrm{~b}}$, Dongxu He $\mathrm{He}^{3, \mathrm{c}}$, Lei Zhao ${ }^{4, \mathrm{~d}}$ \\ ${ }^{1}$ School of Energy Resources, China University of Geosciences, Beijing, 100083, China \\ ${ }^{2}$ Sinopec International Exploration \& Production Corporation, Beijing, 100029, China \\ ${ }^{3}$ Shengli Production Plant, Shengli Oilfield Company, Dongying, Shandong, 257000, China \\ ${ }^{4}$ Petroleum Exploration and Produnction Research Institute, SINOPEC, Beijing 100083, China \\ ahtt10502@163.com, btanxin200300666@126.com, \\ c18905468956@126.com, dray-zhao@163.com
}

Keywords: Structural model, Sedimentary facies model, Property models.

\begin{abstract}
After 40 years of water flooding development, Putaohua oil formation of Xingshugang oil field had already entered the stage of high water cut, and the comprehensive water cut has been more than $92 \%$. Not only the distribution relationship of oil and gas becomes more complex, but also the fluid property and pore structure have been greatly affected due to the injection of water, resulting the reservoir heterogeneity becomes more serious. Thus three-dimensional geological modeling need to be established to provide reasonable geological model for production of high water cut period. In this paper, deterministic modeling and stochastic simulation methods are used to establish the structural model, sedimentary facies model and property models under facies control, which laying the foundation for the reservoir numerical simulation.
\end{abstract}

\section{Introduction}

Geological model refers to the data body of underground geological features and three-dimensional spatial distribution of the reservoir [1-3], which can be expressed quantitatively. From the point of three-dimensional of the reservoir quantitative research, the three-dimensional model was established, which aimed to the multidisciplinary integration, three-dimensional quantification and visualization of prediction for inter-well reservoir $[4,5]$.

Take Putaohua oil formation of Xingshugang oil field as the target layer, on the basis of the analysis of the geological conditions of the reservoir with the combination of point, face, body, static and dynamic, using actual data, the three-dimensional geological model was established in line with the regional geological structure, physical properties, and property. Therefore, this study is based on facies-controlled modeling, which first established the sedimentary facies model, followed with distribution feature of reservoir parameters in term of different microfacies control to interpolate between wells and simulate stochastically, thereby reservoir property models were established. The advantage of this method is that the reservoir property is in line with the selected sedimentary facies distribution, at the same time, constraint with geological parameters varies due to different sedimentary facies, reflecting the fine modeling features and laying a good foundation for numerical simulation.

\section{Regional Geological Condition}

After 40 years of exploration and development, Xingshugang Oil field had already entered the stage of high water cut, and had extensive drilling data. The study area has 676 development wells with area about $7 \mathrm{~km}^{2}$ and average well spacing about $100 \mathrm{~m}$. Schlumberger Petrel software was used in the reservoir modeling to complete the structure modeling, sedimentary facies modeling and physical modeling. 


\section{Data Preparation and Modeling Strategy}

There are some preliminary data preparation works in reservoir geological modeling, typically include:

1) The top surface tectonic data of the target layer;

2) Fault interpretation data;

3) Well location coordinates, well deviation data, strata division data of single well, etc.;

4) Single well log curve, porosity and permeability data derived from log interpretation;

5) Seismic property data or other data which can play the role of data constraint.

The main strategies of this model are as follows:

1) The combination of deterministic modeling and stochastic modeling, and the principle of human-computer interaction;

2) Three-steps modeling strategy, namely the structural model, the sedimentary facies model and the porosity and permeability models;

3) Multi-information coordinated modeling strategy.

\section{Structural Model}

Structural model is the foundation of geological modeling and provides a three-dimensional modeling framework for the property modeling, including fault model and layer model. Fault model controls the boundary and configuration relationship of fault blocks, but also controls the terrain fluctuation of model. The Petrel software does not recognize the fault contact relationship, therefore need to be treated under following three basic principles: a) Clear the development history of fracture system, and the late fault can not be cut by the early fault; b) The main fault and the subordinate fault need to be distinguished, and the main fault does not allow to be cut; c) Contact relationship between faults need to be defined, and the fault plane may intersect but not cut. A total of 7 high-angle normal faults are developed in study area, and the spatial distribution of fault model is shown in Fig. 1.

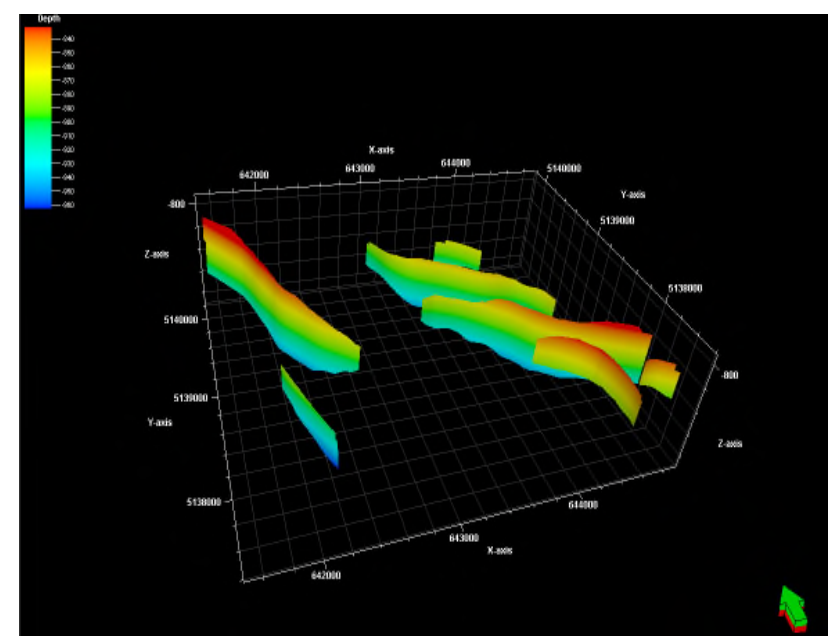

Fig. 1 Fault model.

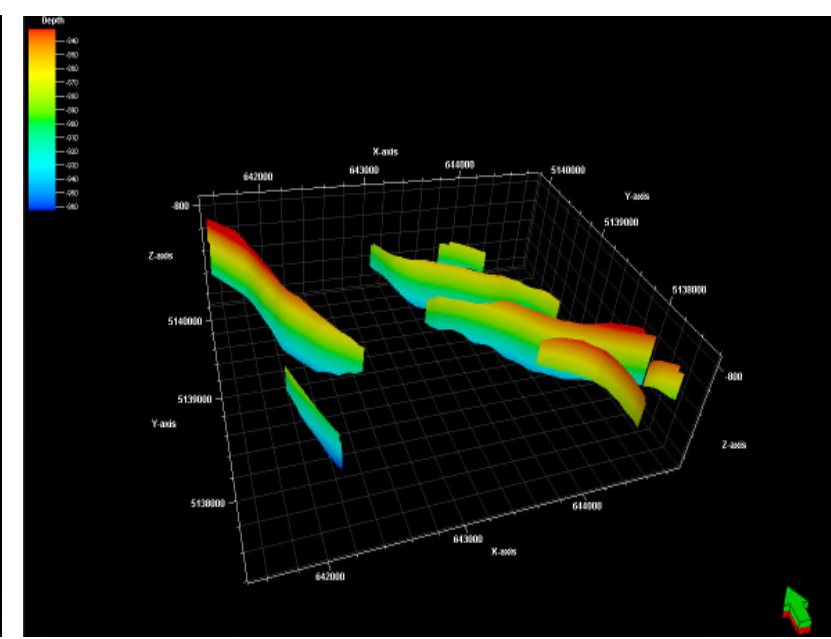

Fig. 2 Layer model.

With the surface interpolation using the minimum curvature method by strata division data, layer model controls the distribution of formation in space, thus forming the top and surface of sub-layers. Geologic properties between different strata are different because of different geological structures. Establishing the layer model should pay attention that the sub-layer interface is faithful to the strata division data and tectonic interface effectively reflect the whole tectonic patterns and trends (Fig. 2).

In order to ensure accuracy and avoid too large number of grid computing, the model plane grid uses the grid resolution of $25 \mathrm{~m} \times 25 \mathrm{~m}$, to be able to characterize the thin sand body of $0.5 \mathrm{~m}$ in vertical and 128 vertical grids were divided, while the final grid resolution is $136 \times 128 \times 128$ and the total number of grids is $2,228,224$. 


\section{Sedimentary Microfacies Model}

On the basis of sedimentary microfacies preliminary results, sedimentary microfacies model was established in research area by deterministic modeling method (Fig. 3), and determined the position of each sedimentary microfacies distribution and configuration relationship on three-dimensional space. General characteristics of sedimentary facies in the study area is the major channels with best physical property are surrounded by channel belts with second best property; Channel belts are surrounded by interchannel sandbodies with third best property; Interchannel sandbodies are surrounded by flood mud with the worst property. The establishment of sedimentary facies model conducts effective constraint for the next modeling of porosity and permeability.

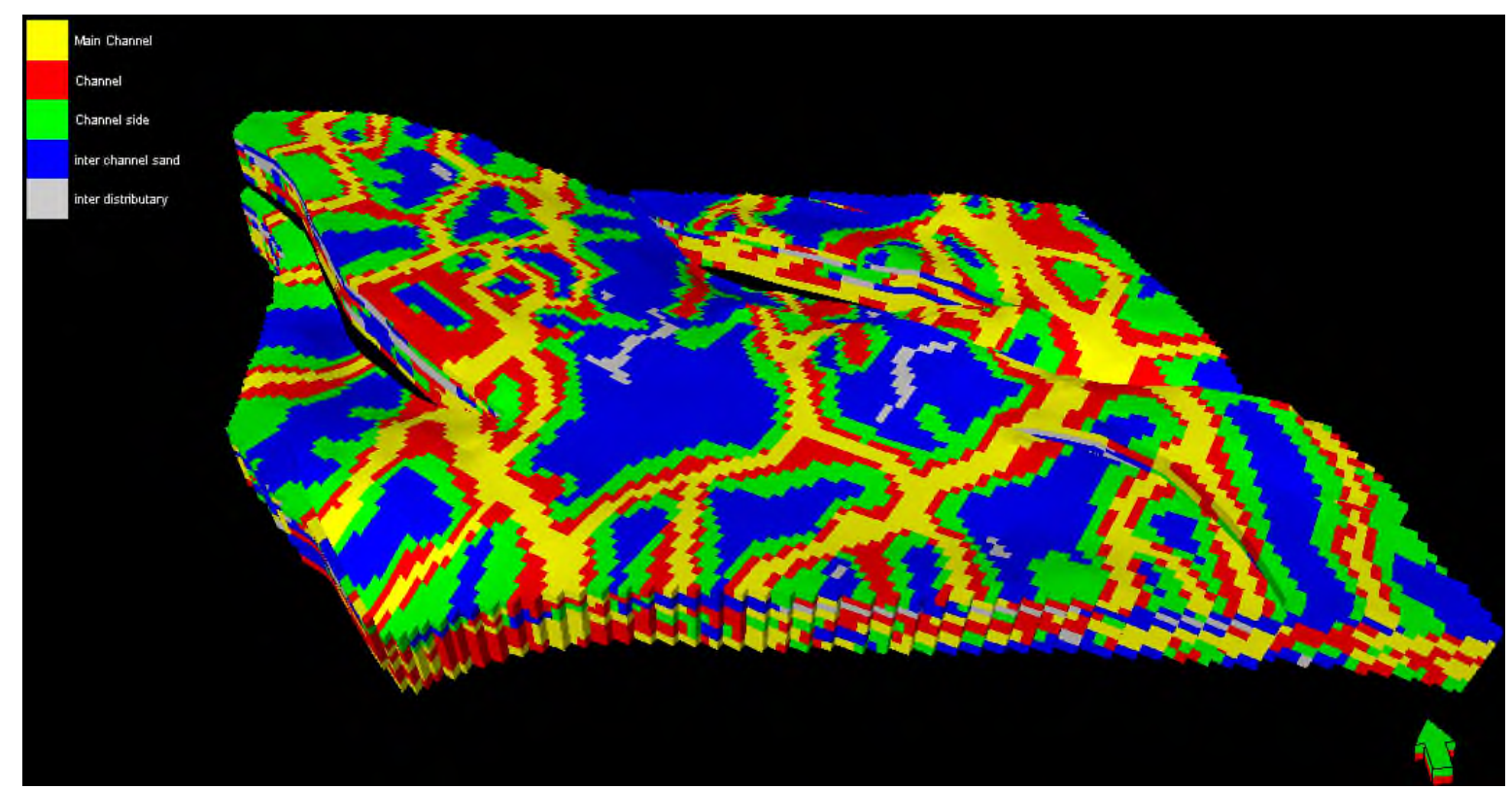

Fig. 3 Sedimentary microfacies model.

\section{Property Model}

By petroleum geology, reservoir studies and production experience, we can clearly recognize the physical property and the distribution of oil are controlled by sedimentary microfacies, therefore distribution of physical property of different sedimentary microfacies is different. Property model under control by sedimentary microfacies, namely takes the modeling results of sedimentary microfacies as constraint. According to the distribution law of reservoir parameters under different sedimentary microfacies to conduct interwell interpolation between wells or simulate stochastically, porosity and permeability models were achieved (Fig. 6 - Fig. 9). Under the facies model constraint, property models are highly in line with geological phenomenon and can effectively avoid the most demanding requirements for stability of continuous variables model [6], and thus truly reflect the underground reservoir physical characteristics, and reduce the uncertainty of reservoir modeling results. Reservoir stochastic modeling research have many ways, while in this study sequential Gaussian simulation method was used.

Take P1-1-1 layer for example, variation function analysis was performed for porosity and permeability (Table 1, Table 2 and Fig. 4, Fig. 5). There tend to have a definite relation between porosity and permeability, thus the longitudinal direction of permeability and porosity and the distribution direction of microfacies were substantially the same. From the permeability data, its range of variation is much larger than that of porosity, and the reason for this phenomenon is that factors of permeability influenced are more than that of porosity. Therefore, for the same microfacies and the same sub-layer, the range of porosity variation is greater than permeability, namely the spatial continuity of permeability is worse. 
Table 1. Variation function analysis of porosity (P1-1-1).

\begin{tabular}{|c|c|c|c|c|c|c|}
\hline Layers & $\begin{array}{c}\text { Sedimentary } \\
\text { Microfacies }\end{array}$ & Type & $\begin{array}{c}\text { Major } \\
\text { direction }\end{array}$ & $\begin{array}{c}\text { Minor } \\
\text { Direction }\end{array}$ & $\begin{array}{c}\text { Vertical } \\
\text { Direction }\end{array}$ & Direction \\
\hline P1-1-1 & main channel & spherical & 380.5 & 167.2 & 3.3 & 348 \\
\hline P1-1-1 & channel belt & spherical & 266.9 & 139.2 & 2.2 & 342 \\
\hline P1-1-1 & channel boundary & spherical & 253.7 & 183.2 & 1.3 & 335 \\
\hline P1-1-1 & interchannel sandbody & spherical & 395.2 & 202.8 & 1.9 & 353 \\
\hline P1-1-1 & Interdistributary bay & spherical & 125.2 & 68.5 & 2.2 & 334 \\
\hline
\end{tabular}

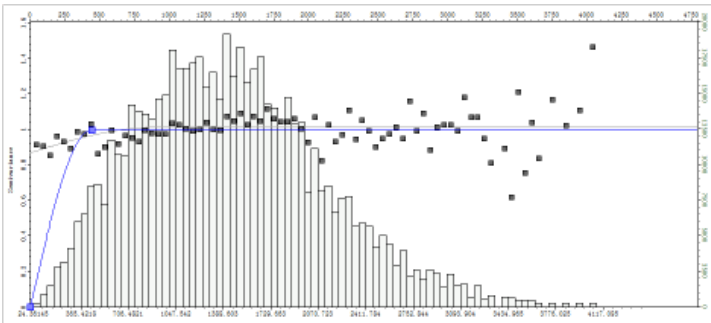

Major direction of main channel

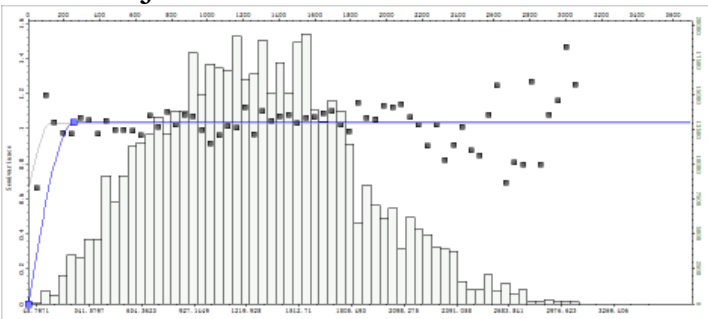

Major direction of channel belt

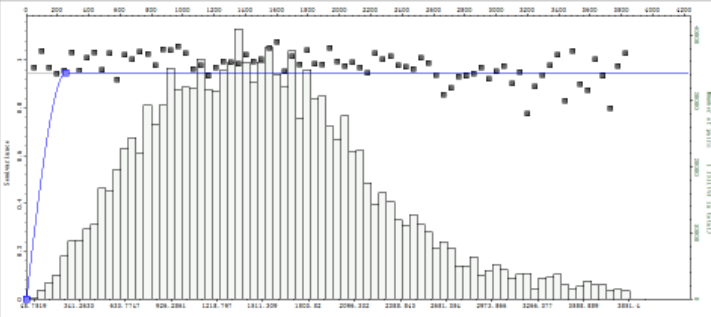

Major direction of channel boundary

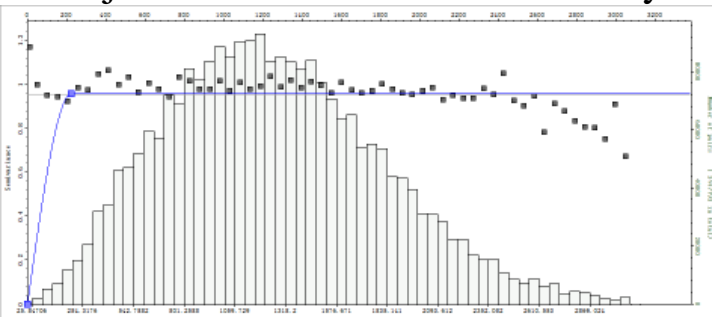

Major direction of interchannel sandbody

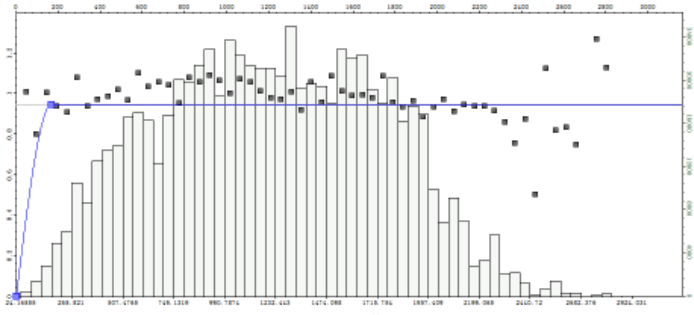

Minor direction of main channel

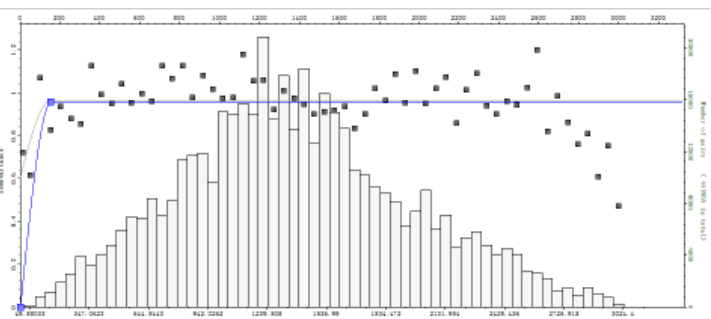

Minor direction of channel belt

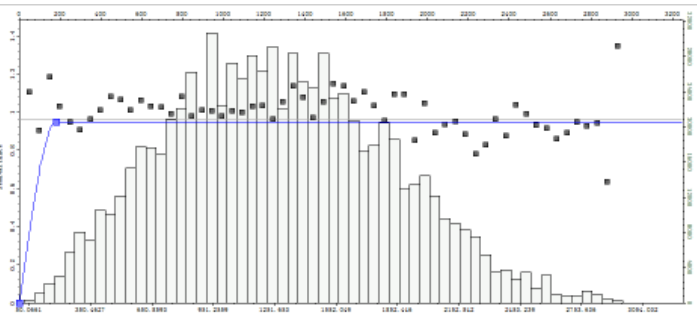

Minor direction of channel boundary

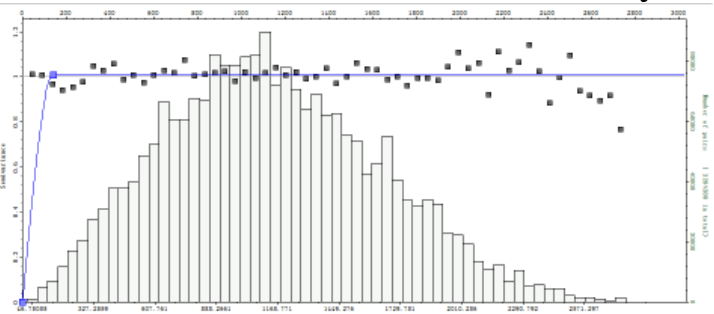

Minor direction of interchannel sandbody Fig. 4 Variation function analysis of porosity(P1-1-1).

Table 2. Variation function analysis of permeability (P1-1-1).

\begin{tabular}{|c|c|c|c|c|c|c|}
\hline Layers & $\begin{array}{c}\text { Sedimentary } \\
\text { Microfacies }\end{array}$ & Type & $\begin{array}{c}\text { Major } \\
\text { direction }\end{array}$ & $\begin{array}{c}\text { Minor } \\
\text { Direction }\end{array}$ & $\begin{array}{c}\text { Vertical } \\
\text { Direction }\end{array}$ & Direction \\
\hline P1-1-1 & Main channel & Spherical & 393.2 & 162 & 2.9 & 345 \\
\hline P1-1-1 & Channel belt & Spherical & 229.9 & 138.2 & 1.4 & 339 \\
\hline P1-1-1 & Channel boundary & Spherical & 157.2 & 137.1 & 1.3 & 351 \\
\hline P1-1-1 & Interchannel sandbody & Spherical & 219.1 & 124.1 & 1.8 & 341 \\
\hline P1-1-1 & Interdistributary bay & Spherical & 124.8 & 80.5 & 0.9 & 334 \\
\hline
\end{tabular}




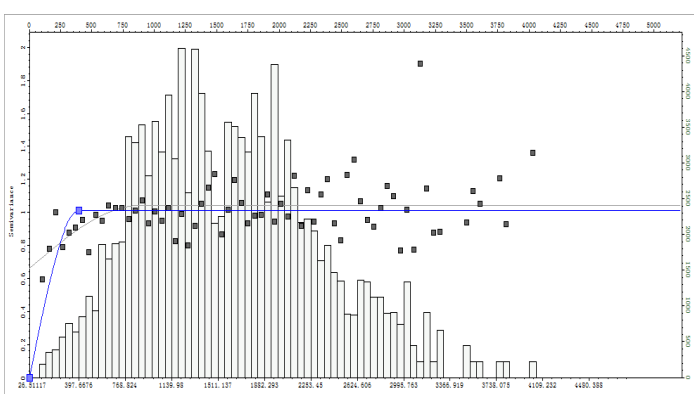

Major direction of main channel

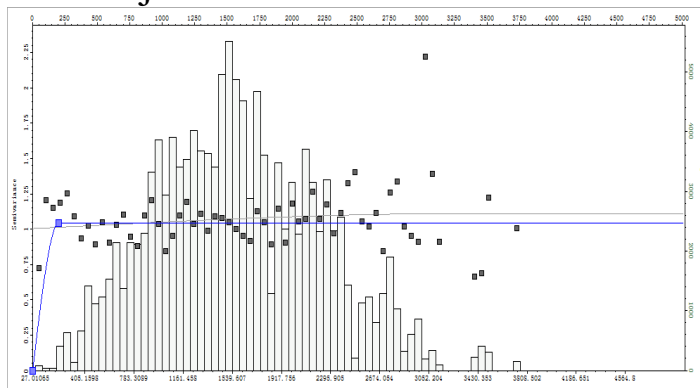

Major direction of channel belt

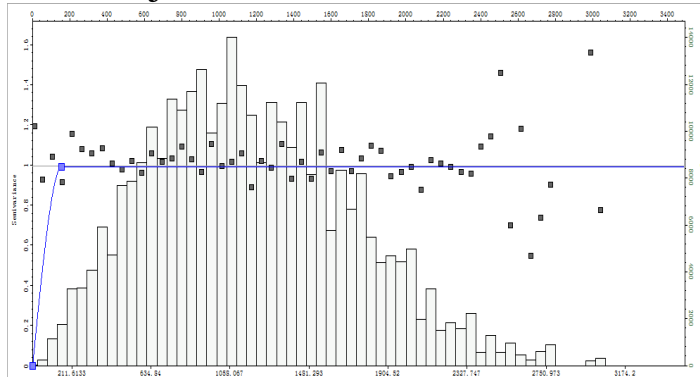

Major direction of channel boundary

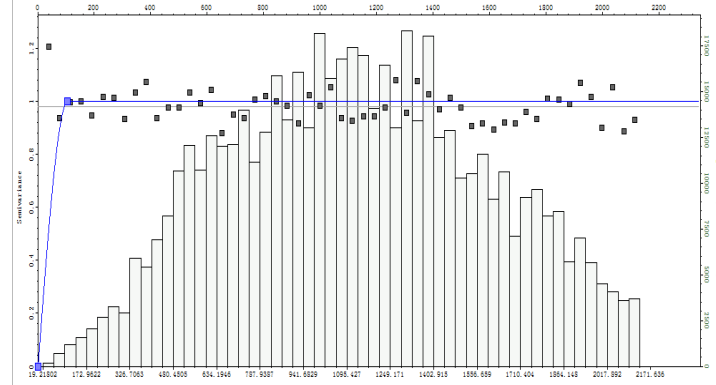

Major direction of interchannel sandbody

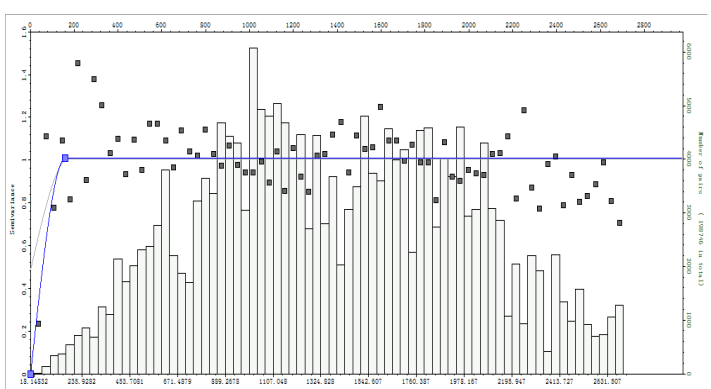

Minor direction of main channel

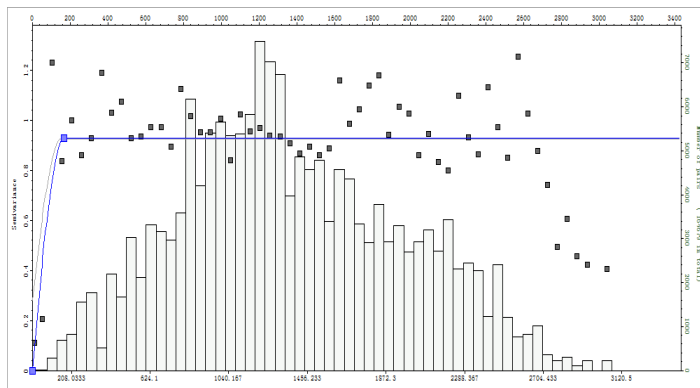

Minor direction of channel belt

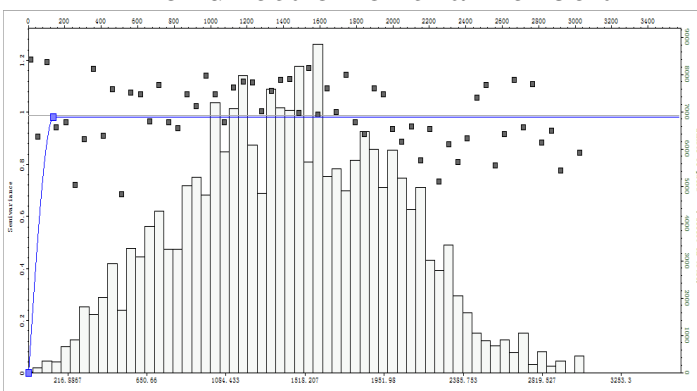

Minor direction of channel boundary

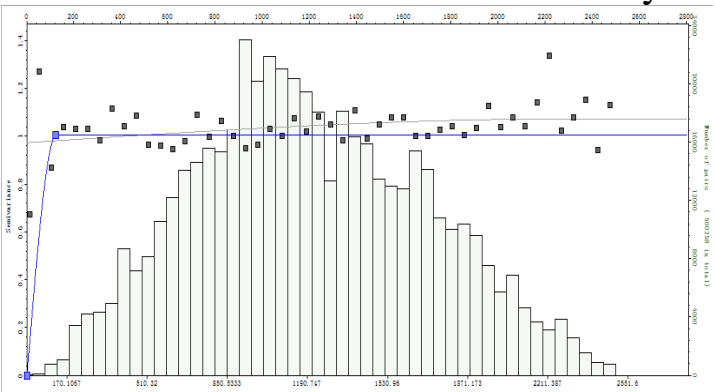

Minor direction of interchannel sandbody

Fig. 5 Variation function analysis of permeability(P1-1-1).

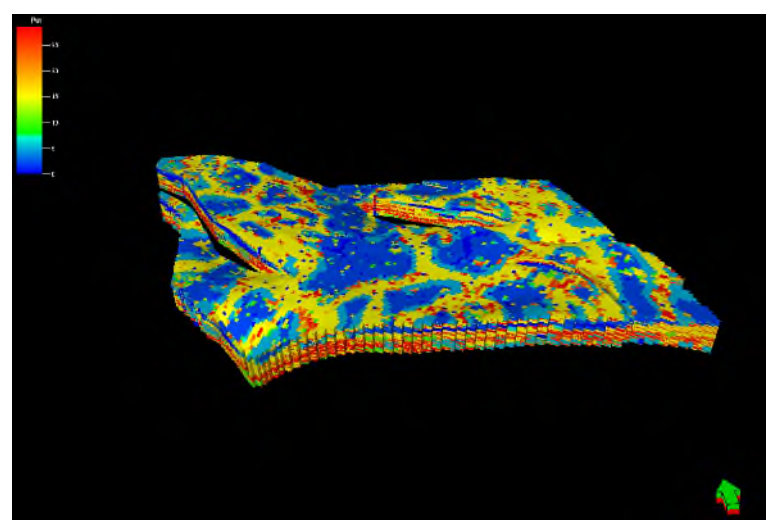

Fig. 6 Porosity model.

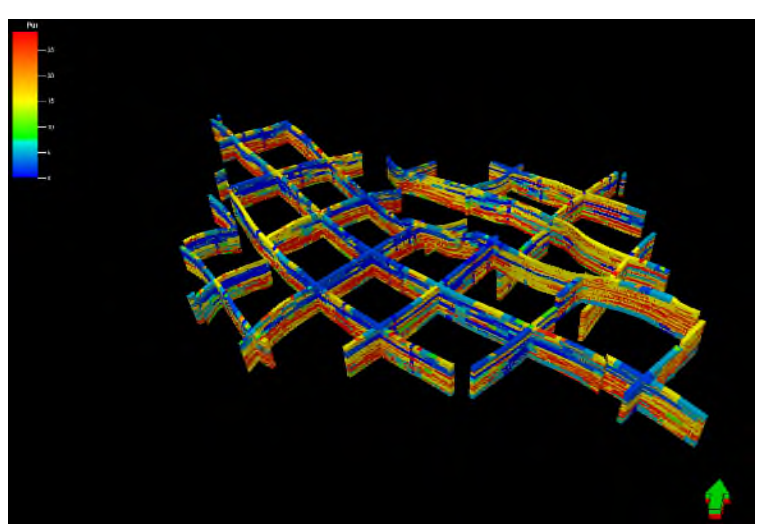

Fig. 7 The fence diagram of porosity model. 


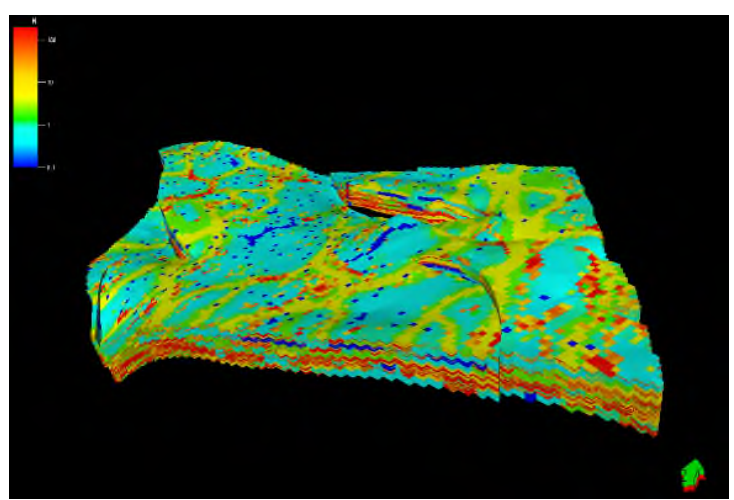

Fig. 8 Permeability model.

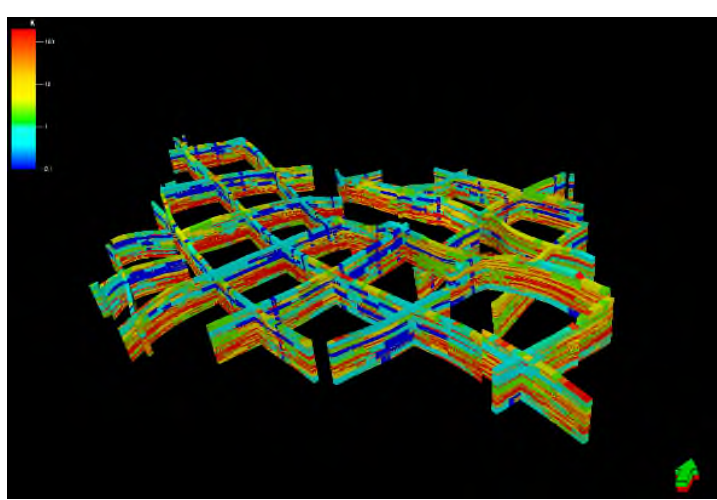

Fig. 9 The fence diagram of permeability model.

\section{Conclusion}

Accurate basic data, the complexity of tectonic, and the relationship between fault and layer are the important basis of fine three-dimensional geological modeling. In this district, the use of combining deterministic modeling method and stochastic modeling method, structural model, sedimentary facies model and property models controlled by facies were established. By variation function adjustment under different sedimentary microfacies constraint, porosity model and permeability model were established. The major direction of property model has little difference. Due to different thickness of sedimentary microfacies, the vertical direction changes slightly different. For the same microfacies and the same sub-layer, the range of porosity variation is greater than permeability, namely the spatial continuity of permeability is worse.

\section{Acknowledgement}

This work is supported by the Romania's Operational Program for Human Resource Development (POSDRU), financed from the European Social Fund and the Romanian Government under the contract number POSDRU/159/1.5/S/134398.

\section{References}

[1] Petri Nets Tools - https://www.informatik.uni-hamburg.de/TGI/PetriNets/tools/quick.html.

[2] L. Pistol and R. Țoniş (Bucea-Manea) Model of Innovation through Information Network Sharing, - J. Appl. Econom. Series, 4(34) (2015) 509-513.

[3] R. Ţoniş Bucea-Manea, M. G. Catană and S. Tonoiu, Network Business Environment for Open Innovation in SMEs, Appl. Mech. Mater. 760 (2015) 751-756.

[4] Zachman architecture - http://www.zachman.com/about-the-zachman-framework.

[5] Making Work Flow: On the Application of Petri Nets to Business Process Management W.M.P. van der Aalst? Department of Technology Management, Eindhoven University of Technology. http://wwwis.win.tue.nl/ wvdaalst/publications/p153.pdf

[6] S. Jablonski and C. Bussler, Workflow Management: Modelling Concepts, Architecture, and Implementation, International Thomson Computer Press, London, UK, 1996.

[7] C. Menard, The Economics of Hybrid Organizations. J. Inst. Theor. Econom. 160 (2004) $345-376$.

[8] G. Perrone, L. Scarpulla and L. Cuccia, Fostering SMEs networking through Business Ecosystem and ICT, ERIMA07' Proceedings, Italy, (2007) 154-162. 
[9] M. Snoeck and K. U. Leuven, Business Process Verification: a Petri Net Approach Manu De Backer, Dept. of Applied Economic Sciences, Naamsestraat 69, B-3000 Leuven, Belgium. http://core.ac.uk/download/files/153/6338942.pdf

[10] J. Chen, H. Xiong, L. Han, K. Zheng and G. Gao, A Modeling Method in Financial Work on Using Petri Nets, J. Inform. Comput. Sci. 9(6) (2012) 1625-1632.

[11]Colour Petri Nets Tools - http://cpntools.org/

[12]M. Zäuram, Business Process Simulation Using Coloured Petri Nets, Master's Thesis, http://webcache.googleusercontent.com/search?q=cache:nuMJvIfvA4cJ:comserv.cs.ut.ee/forms/ati_ report/downloader.php\%3Ffile\%3DB588E43D2D553E437CC37B032C2429ECFA3D2B83+\&cd=1 $\& \mathrm{hl}=\mathrm{en} \& \mathrm{ct}=\mathrm{clnk} \& \mathrm{gl}=\mathrm{ro}$

[13]K. Jensen, Aarhus University, Denmark, Dining Philosophers http://cpntools.org/_media/ documentation/diningphilosophers.pdf 